\title{
ANALISIS PROPAGASI KETIDAKPASTIAN PADA PENENTUAN VISKOSITAS MENGGUNAKAN BOLA-JATUH
}

\author{
Entjie Mochamad Sobbich, Bimbing Atedi
}

\begin{abstract}
Abstrak
Viskositas adalah besaran ukur yang sangat penting di bidang otomotif khususnya berkaitan dengan pelumasan atau upaya untuk meminimisasi friksi antara elemen yang saling bergesekan. Walaupun viskositas bukan besaran pokok, seperti massa dan panjang, namun bukan berarti bahwa ketelitian tidak perlu diperhatikan. Pada pengukuran viskositas, orang bisa menggunakan alat ukur yang disebut dengan viskometer bola-jatuh. Alat ukur ini sederhana, bekerja berdasarkan keseimbangan gaya-gaya yang bekerja pada bola jatuh yang bergerak di dalam sampel cairan.

Di dalam makalah ini, dianalisis proses propagasi ketidakpastian viskositas dari viskometer bola-jatuh dan contoh numerik diberikan untuk memberikan gambaran dampak ketidakpastian dari masing-masing parameter. Untuk masukan numerik $g=9,78065 \pm 0,00002 \mathrm{~m} / \mathrm{s}^{2} ; \mathrm{r}=0,125 \pm 0,002 \mathrm{~m} ; \mathrm{d}_{\mathrm{s}}=997,2 \pm 0,1 \mathrm{~kg} / \mathrm{m}^{3} ; \mathrm{d}_{\mathrm{l}}=980,5 \pm 0,1$ $\mathrm{kg} / \mathrm{m}^{3} ; \mathrm{v}=0,234 \pm 0,001 \mathrm{~m} / \mathrm{s}$ dihasilkan viskositas $\eta=2,42 \pm 0,05 \mathrm{~kg} / \mathrm{m} . \mathrm{s}$.

Selain itu, semua kontributor berada pada orde desimal kedua kecuali dari gravitasi yang berada pada desimal ke enam $\left(=5 \times 10^{-6}\right)$. Dengan demikian, gravitasi dapat dipandang sebagai kontributor yang sangat kecil dan dapat diabaikan.

Kata kunci: viskositas, propagasi ketidakpastian, bola jatuh.
\end{abstract}

\section{Abstract}

Viscosity is a significant variable in automotive field especially related to lubrication or to eliminating friction between moving elements. Though viscosity is not basic quantity like e.g. mass and length, it is not meant that accuracy should not be considered.

In measuring viscosity, we can use a measuring instrument called as Falling-Ball Viscometer. This instrument is simple, worked based on the principle of equilibrium of forced excerted on the falling ball which moving in the sample liquid.

Propagation of uncertainty on the determination of viscosity using falling ball viscometer was analysed in this paper. Numerical example was given to shown the influence of uncertainty of each parameters. For $g=$ $9,78065 \pm 0,00002 \mathrm{~m} / \mathrm{s}^{2} ; \quad r=0,125 \pm 0,002 \mathrm{~m} ; d_{\mathrm{s}}=997,2 \pm 0,1 \mathrm{~kg} / \mathrm{m}^{3} ; d_{l}=980,5 \pm 0,1 \mathrm{~kg} / \mathrm{m}^{3} ; \mathrm{v}=0,234 \pm 0,001$ $\mathrm{m} / \mathrm{s}$ was calculated the viscosity $\eta=2,42 \pm 0,05 \mathrm{~kg} / \mathrm{m} . \mathrm{s}$.

Besides, all contributor lies at second order decimal unless the gravitation lies at the six order decimal $(=5 \times 10$ 6). Therefore, gravitation can be considered as the negligible contributor.

Keyword: viscosity, uncertainty propagation, falling ball.

\section{PENDAHULUAN}

Membicarakn masalah standardisasi maupun kualitas di bidang otomotif tentu orang tidak lepas dari pembahasan tentang kualitas dari oli pelumas. Pemeliharaan komponen-komponen otomotif yang bergerak dan saling bergesekan, seperti halnya torak dan silindernya, maka pelumasan diperlukan berkenaan dengan pemeliharaan komponen. Oli pelumas yang berkualitas mampu menjaga komponenkomponen yang bergesekan pada kondisi terbaiknya dan menahan terjadinya aus pada komponen. Viskositas adalah besaran utama yang menjadi perhatian dari oli pelumas. Oleh karena itu, perhatian terhadap ketelitian pengukuran viskositas menjadi materi yang penting di bidang otomotif.

Pengukuran kini dianggap tidak lengkap jika hanya menyajikan data hasil pengukuran berupa nilai nominal saja tanpa menyertakan reportase yang menunjukkan adanya nilai ketidakpastian pengukuran. Ini dikarenakan setiap pengukuran tidak pernah memberikan nilai ukur yang mutlak benar, didalamnya akan selalu terkandung kesalahan-kesalahan. Faktorfaktor yang dianggap berpengaruh terhadap terjadinya kesalahan pengukuran ini ada yang bersifat acak (random) dan ada yang bersifat sistematis. 
Di dalam makalah ini dibahas proses propagasi ketidakpastian pada pengukuran viskositas menggunakan viskometer bola-jatuh. Berdasarkan Hukum Stoke, viskositas ternyata ditentukan oleh beberapa parameter atau besaran-besaran lain. Besaran-besaran tersebut adalah: diameter bola, densitas bola, densitas cairan, kecepatan pergerakan bola, dan gravitasi.

Dengan contoh numerik akan dihasilkan gambaran besarnya kontributor ketidakpastian dari masing-masing komponen. Untuk masukan numerik: $g=9,78065 \pm 0,00002 \mathrm{~m} / \mathrm{s}^{2} ; r=0,125$ $\pm 0,002 \mathrm{~m} ; d_{\mathrm{s}}=997,2 \pm 0,1 \mathrm{~kg} / \mathrm{m}^{3} ; \mathrm{d}_{\mathrm{l}}=980,5 \pm$ $0,1 \mathrm{~kg} / \mathrm{m}^{3} ; \mathrm{v}=0,234 \pm 0,001 \mathrm{~m} / \mathrm{s}$ dihasilkan viskositas $\eta=2,42 \pm 0,05 \mathrm{~kg} / \mathrm{m}$.s. Analisis terhadap masing-masing kontributor menunjukkan bahwa terdapat satu-satunya kontributor dengan nilai sangat kecil yaitu gravitasi yang memberikan kontribusinya sebesar $5 \times 10^{-6}$.

\section{DASAR TEORI}

\subsection{Fenomena Viscositas}

Viskositas adalah sifat dari cairan yang menunjukkan adanya hambatan-dalam, artinya bila di dalam cairan terdapat benda yang bergerak maka pergerakan dari benda "dihambat" oleh viskositas cairan. Makin besar nilai viskositas cairan, makin besar pula hambatan yang diberikan. Bila digambarkan sebagai fenomena gaya maka arah dari gaya viskositas ini adalah berlawanan dengan arah dari pergerakan benda, seperti ditunjukkan pada Gambar 1 berikut.

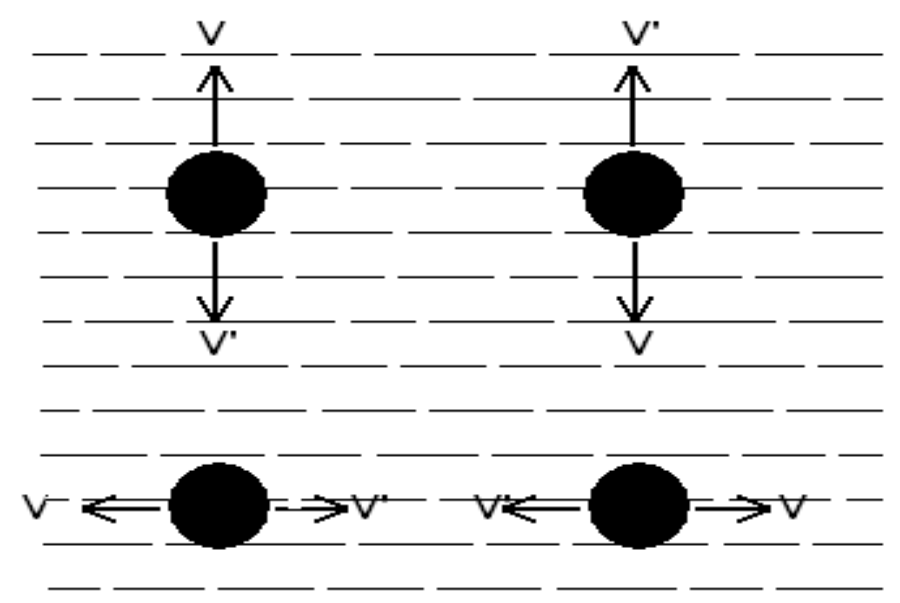

Gambar 1 Arah dari "Hambatan" Viskositas (V) selalu

Berlawanan Arah dengan Arah Pergerakan Benda (V).

\subsection{Prinsip Kerja Viskometer Pada Umumnya}

Viskometer ada banyak macamnya. Namun secara garis besar bisa dibedakan menjadi dua kategori, yaitu :

1. Viskometer yang bekerja dengan cara mengalirkan cairan, termasuk di dalam kategori ini adalah viskometer kapiler (misal Ubbelohde), viskometer Effluc-cup (misal Saybolt, Furol, Zahn cup).

2. Viskometer yang bekerja dengan cara menggerakkan suatu benda di dalam cairan dengan cara membiarkan bola jatuh (misal viskometer bola-jatuh), viskometer rotasi (misal viskometer Brookfield).

Diantara kedua kategori tersebut di atas, ada viskometer yang mengukur viskositas kinematis (satuan Stoke atau $\mathrm{m}^{2} / \mathrm{s}$ ) dan ada yang mengukur viskositas dinamis (satuan Poise, centi Poise atau $\mathrm{kg} / \mathrm{m} . \mathrm{s}$ ). Kedua besaran ini dihubungkan oleh densitas cairan sebagai berikut:

$$
v=\frac{\mu}{\rho}
$$

dimana:

$$
\begin{array}{ll}
v & \text { viskositas kinematis, }\left(\mathrm{m}^{2} / \mathrm{s}\right) \\
\mu & \text { viskositas dinamis, }(\mathrm{kg} / \mathrm{m} . \mathrm{s}) \\
\rho & \text { densitas, }\left(\mathrm{kg} / \mathrm{m}^{3}\right) .
\end{array}
$$


Catatan:

Notasi untuk viskositas dinamis ada yang menuliskan $\mu$ (myu) tetapi ada yang menggunakan notasi $\eta(n u)$. Di dalam makalah ini dua-duanya digunakan.

1 Poise $=0,1 \mathrm{~kg} / \mathrm{m} . \mathrm{s} ; 1$ Stoke $=10^{-4} \mathrm{~m}^{2} / \mathrm{s}$.

\subsection{Viskometer Bola-Jatuh}

Viskometer bola-jatuh adalah alat ukur viskositas cairan yang beroperasi dengan cara melepaskan sebuah bola di dalam cairan yang akan

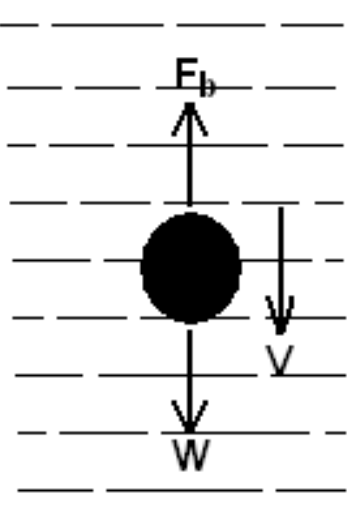

ditentukan viskositasnya. Bila kita bayangkan bahwa cairan tidak memiliki faktor penghambat, yaitu viskositas, maka saat bola bergerak dengan kecepatan terminalnya di dalam cairan maka bola dipengaruhi oleh gaya berat $\mathrm{W}$ dan gaya angkat $F_{b}$, seperti digambarkan pada Gambar 2.a. Dengan adanya hambatan viskos dari cairan maka terdapat tambahan gaya $F$ yang arahnya berlawanan arah gerak bola, seperti digambarkan pada Gambar 2.b.

Gambar 2 Gaya-gaya yang Bekerja pada Bola yang Bergerak di dalam Cairan

a. Bila cairan tidak mempunyai viskositas

b. Bila cairan memiliki viskositas.

\subsection{Hukum Stoke dan Model Matematis}

Seorang ahli matematika dan fisika dari Inggris yang bernama G.G. Stoke (1819 - 1903) berhasil menyatakan besarnya gaya hambat viskos yang selanjutnya terkenal dengan sebutan hokum Stoke, yaitu :

$$
F_{v}=6 \pi \eta r v
$$

dimana:

$$
\begin{array}{ll}
\text { Fv } & \text { gaya viskos, }(\mathrm{N}) \\
\eta & \text { viskositas dinamis, }(\mathrm{kg} / \mathrm{m} . \mathrm{s}) \\
r & \text { jari-jari bola, }(\mathrm{m}) \\
\mathrm{v} & \text { kecepatan terminal jatuhnya bola, }(\mathrm{m} / \mathrm{s}) .
\end{array}
$$

Gaya berat W juga disebut sebagai gaya gravitasi, arahnya selalu ke bawah. Biasanya ditentukan dari :

$$
W=\frac{4}{3} \pi r^{3} g d_{s}
$$

dimana:

$$
\begin{array}{ll}
\text { W } & \text { gaya gravitasi, }(\mathrm{N}) \\
\mathrm{g} & \text { gravitasi, }\left(\mathrm{m} / \mathrm{s}^{2}\right) \\
\mathrm{d}_{\mathrm{s}} & \text { densitas bola, }\left(\mathrm{kg} / \mathrm{m}^{3}\right)
\end{array}
$$

Gaya angkat (buoyancy) Fb adalah gaya yang dilakukan oleh adanya massa cairan yang dipindahkan oleh bola. Besarnya dapat ditentukan dari:

$F_{b}=\frac{4}{3} \pi r^{3} g d_{l}$

dimana:

$\mathrm{F}_{\mathrm{b}} \quad$ gaya angkat, $(\mathrm{N})$

$\mathrm{d}_{1}$ densitas cairan, $\left(\mathrm{kg} / \mathrm{m}^{3}\right)$

Pada saat bola bergerak dengan kecepatan terminalnya yang konstan maka berlaku keseimbangan ketiga gaya tersebut di atas. Sehingga dari persamaan (2), (3) dan (4)

Dihasilkan model matematis (atau disebut 
dengan rumus reduksi) untuk viskometer bolajatuh, yaitu:

$$
\eta=\left(\frac{2 g r^{2}}{9 v}\right)\left(d_{s}-d_{l}\right)
$$

\section{PROPAGASI KETIDAKPASTIAN}

Propagasi ketidakpastian adalah peristiwa terakumulasinya ketidakpastian suatu besaran dari beberapa besaran penentunya. Jika sebuah besaran y merupakan fungsi dari besaranbesaran penentuanya $x_{1}, x_{2}, x_{3}, \ldots, x_{n}$ maka dapat dituliskan:

$$
y=f\left(x_{1}, x_{2}, x_{3}, \ldots, x_{n}\right)
$$

Variabel y adalah besaran yang umumnya disebut sebagai variabel tak bebas, artinya nilai dari variabel $y$ ditentukan dari nilai-nilai $x_{1}, x_{2}$, $\mathrm{x}_{3}, \ldots, \mathrm{x}_{\mathrm{n}}$. Besaran-besaran $\mathrm{x}_{1}, \mathrm{x}_{2}, \mathrm{x}_{3}, \ldots, \mathrm{x}_{\mathrm{n}}$ adalah besaran-besaran hasil pengukuran, umum disebut sebagai variabel bebas.

Apabila masing-masing $x_{i}(i=1,2,3, \ldots, n)$ bersifat tidak berkorelasi atau berkorelasi lemah dan masing-masing $x_{i}$ memiliki ketidakpastian baku $\mathrm{u}\left(\mathrm{x}_{\mathrm{i}}\right)$ maka ketidakpastian dari $\mathrm{y}, \mathrm{u}(\mathrm{y})$, dapat ditentukan dari:

$$
u^{2}(y)=\sum_{i=1}^{n}\left(\frac{\partial f}{\partial x_{i}}\right) u^{2}\left(x_{i}\right)
$$

dimana

u(y) ketidakpastian dari y $\frac{\partial f}{\partial x_{i}}$ turunan-parsial $\mathrm{f}$ terhadap $\mathrm{x}_{\mathrm{i}}$, (juga disebut koefisien sensitivitas)

$\mathrm{u}\left(\mathrm{x}_{\mathrm{i}}\right)$ ketidakpastian baku dari variable $\mathrm{x}_{\mathrm{i}}$.

\section{KOEFISIEN SENSITIVITAS}

Dari persamaan (5) dan (7) maka koefisien sensitivitas untuk masing-masing besaran: gravitasi $\mathrm{g}$, kecepatan $\mathrm{v}$, diameter bola $\mathrm{d}$, densitas bola $d_{s}$, dan densitas cairan $d_{l}$, diperoleh sebagai berikut:

$$
\left(\frac{\partial \eta}{\partial r}\right)=\frac{4}{9} \frac{g r\left(d_{s}-d_{l}\right)}{v}
$$

$$
\left(\frac{\partial \eta}{\partial d_{s}}\right)=\frac{2}{9} \frac{g r^{2}}{v}
$$

$\left(\frac{\partial \eta}{\partial g}\right)=\frac{2}{9} \frac{r^{2}\left(d_{s}-d_{l}\right)}{v}$

$\left(\frac{\partial \eta}{\partial d_{l}}\right)=\frac{2}{9} \frac{g r^{2}}{v}$

$\left(\frac{\partial \eta}{\partial v}\right)=\frac{2}{9} \frac{g r^{2}\left(d_{s}-d_{l}\right)}{v^{2}}$

\section{MODEL KETIDAKPASTIAN}

Dari persamaan (7) dan (8) di atas maka model ketidakpastian untuk perhitungan propagasi ketidakpastian sebuah viscometer bola-jatuh adalah:

$$
u(\eta)=\frac{2}{9} \sqrt{4 \frac{\left.g^{2} r^{2}\left(d_{s}-d_{l}\right)^{2} u(r)\right)^{2}}{v^{2}}+\frac{g^{2} r^{4}\left[\left(u\left(d_{s}\right)\right)^{2}+\left(u\left(d_{l}\right)\right)^{2}\right]}{v^{2}}+\frac{r^{4}\left(d_{s}-d_{l}\right)^{2}(u(g))^{2}}{v^{2}}+\frac{g^{2} r^{4}(d s-d l)^{2}(u(v))^{2}}{v^{4}}}
$$

\section{CONTOH NUMERIK}

Untuk memberikan "sense" terhadap kemungkinan besarnya kontribusi dari masingmasing besaran yang berpengaruh maka dapat dilakukan dengan cara memasukkan nilai-nilai numerik berdasarkan estimasi yang mungkin berlaku untuk masing-masing besaran ukur.

Anggaplah untuk sistem tertentu berlaku asumsi nilai-nilai numerik berikut: 
Tabel 1 Asumsi Numerik

\begin{tabular}{|l|c|c|}
\hline \multicolumn{1}{|c|}{ Besaran Ukur } & Nilai Estimasi & Estimasi Ketidakpastian Baku \\
\hline Gravitasi $(\mathrm{g})$ & $9,78065 \mathrm{~m} / \mathrm{s}^{2}$ & $\pm 0,00002 \mathrm{~m} / \mathrm{s}^{2}$ \\
Jari-jari bola $(\mathrm{r})$ & $0,125 \mathrm{~m}$ & $\pm 0,001 \mathrm{~m}$ \\
Densitas bola $\left(\mathrm{d}_{\mathrm{s}}\right)$ & $997,2 \mathrm{~kg} / \mathrm{m}^{3}$ & $\pm 0,1 \mathrm{~kg} / \mathrm{m}^{3}$ \\
Densitas cairan $\left(\mathrm{d}_{\mathrm{l}}\right)$ & $980,5 \mathrm{~kg} / \mathrm{m}^{3}$ & $\pm 0,1 \mathrm{~kg} / \mathrm{m}^{3}$ \\
Kecepatan bola $(\mathrm{v})$ & $0,234 \mathrm{~m} / \mathrm{s}$ & $\pm 0,002 \mathrm{~m} / \mathrm{s}$ \\
\hline
\end{tabular}

\section{PERHITUNGAN DAN ANALISIS KONTRIBUTOR}

Dengan estimasi harga masing-masing besaran terukur sebagaimana tercantum pada Tabel $1 \mathrm{di}$

Hasil perhitungannya adalah sebagai berikut:

Koefisien Sensitivitas

$$
\begin{aligned}
& \left(\frac{\partial \eta}{\partial g}\right)=0,25\left(\frac{\mathrm{kg} / \mathrm{m} \cdot \mathrm{s}}{\mathrm{m} / \mathrm{s}^{2}}\right) \\
& \left(\frac{\partial \eta}{\partial d_{s}}\right)=0,15\left(\frac{\mathrm{kg} / \mathrm{m} \cdot \mathrm{s}}{\mathrm{kg} / \mathrm{m}^{3}}\right) \\
& \left(\frac{\partial \eta}{\partial v}\right)=10,36\left(\frac{\mathrm{kg} / \mathrm{m} \cdot \mathrm{s}}{\mathrm{m} / \mathrm{s}}\right)
\end{aligned}
$$

Kontributor Ketidakpastian

$$
\begin{aligned}
& \left(\frac{\partial \eta}{\partial g}\right) u(g)=5 \times 10^{-6}(\mathrm{~kg} / \mathrm{m} . \mathrm{s}) \\
& \left(\frac{\partial \eta}{\partial d_{s}}\right) u\left(d_{s}\right)=0,015(\mathrm{~kg} / \mathrm{m} . \mathrm{s}) \\
& \left(\frac{\partial \eta}{\partial v}\right) u(v)=0,02072(\mathrm{~kg} / \mathrm{m} . \mathrm{s})
\end{aligned}
$$

Viskositas Cairan dan Ketidakpastian

$$
\eta=2,42 \pm 0,05(\mathrm{~kg} / \mathrm{m} . \mathrm{s})
$$

\section{KESIMPULAN}

Telah dilakukan penurunan formula reduksi untuk perhitungan viskositas bila menggunakan viskometer bola-jatuh lengkap dengan analisis propagasi ketidakpastiannya. atas maka dapat dilakukan tahapan perhitungan terhadap koefisien sensitivitas, kontributor ketidakpastian dan akhirnya didapatkan nilai viskositas cairan terhitung serta estimasi ketidakpastiannya.

$$
\begin{gathered}
\left(\frac{\partial \eta}{\partial r}\right)=38,78\left(\frac{\mathrm{kg} / \mathrm{m} \cdot \mathrm{s}}{\mathrm{m}}\right) \\
\left(\frac{\partial \eta}{\partial d_{l}}\right)=0,15\left(\frac{\mathrm{kg} / \mathrm{m} \cdot \mathrm{s}}{\mathrm{kg} / \mathrm{m}^{3}}\right)
\end{gathered}
$$

$$
\begin{array}{r}
\left(\frac{\partial \eta}{\partial r}\right) u(r)=0,03878(\mathrm{~kg} / \mathrm{m} . \mathrm{s}) \\
\left(\frac{\partial \eta}{\partial d_{l}}\right) u\left(d_{l}\right)=0,015(\mathrm{~kg} / \mathrm{m} . \mathrm{s})
\end{array}
$$

Kontributor ketidakpastian viskositas ternyata terdiri dari beberapa besaran ukur: diameter (jari-jari) bola, densitas bola, densitas cairan, kecepatan jatuhnya bola, dan gravitasi. Kontribusi ketidakpastian elementer dari masingmasing komponen besaran ukur terhitung sebesar: gravitasi $=5 \times 10^{-6}(\mathrm{~kg} / \mathrm{m} . \mathrm{s})$, jari-jari bola $=0,03878(\mathrm{~kg} / \mathrm{m} . \mathrm{s})$, densitas bola $=0,015$ 
$(\mathrm{kg} / \mathrm{m} . \mathrm{s})$, densitas cairan $=0,015(\mathrm{~kg} / \mathrm{m} . \mathrm{s})$ serta dari kecepatan gerak bola $=0,02072(\mathrm{~kg} / \mathrm{m} . \mathrm{s})$. Dari angka-angka ini nampak bahwa kontribusi gravitasi jauh lebih kecil dibandingkan kontributor-kontributor lainnya sehingga dapat diabaikan pada perhitungan ketidakpastian viskositas.

\section{DAFTAR PUSTAKA}

1. ISO "Guide to the Expression of the Uncertainty in Measurement" International Organization for Standardisation, Geneva, 1993.

2. R.B. Frenkel, Statistical Background to the ISO Guide to the Expression of Uncertainty in Measurement" Monogr. 2 : NML Technology Transfer Series, TIPP 1242, CSIRO, 2003.

3. Haliday, Resnick, Silaban P., Erwin S., Fisika Jilid 1, Penerbit Erlangga, 1990.

4. Coleman H.W., ands Steele W.G., Experimentation and Uncertainty Analysis for Engineers, John Wiley and Sons, 1999.

5. Wartawan A.L., Minyak Pelumas Pengetahuan Dasar \& Cara Penggunaan, Penerbit P.T. Gramedia, Jakarta, 1983.
6. Holman J.P., Jasjfi E., Metode Pengukuran Teknik, Penerbit Erlangga, Jakarta, 1985.

7. http://physics.nist.gov/Pubs/guidelines/TN12 97/tn1297s.pdf.

\section{BIODATA}

Entjie Mochamad Sobbich, dilahirkan di Surabaya pada tanggal 5 Juli 1955. Penulis menyelesaikan pendidikan terakhir di PINK-ITB di bidang Magister Teknik. Saat ini penulis adalah seorang Peneliti Madya dan menduduki jabatan fungsional pendidikan sebagai Lektor Kepala di Universitas Bina Nusantara. Penulis bekerja di Puslit KIM-LIPI Puspitek Serpong.

H. Bimbing Atedi, dilahirkan di Banyumas pada tanggal 21 Mei 1950. Penulis menyelesaikan pendidikan terakhir di ISTN Jakarta. Penulis mendapatkan gelar kesarjanaan (Ir) jurusan mesin pada tahun 1991. Saat ini penulis bekerja di Puslit KIM-LIPI Puspitek Cisauk Tangerang. Penulis adalah seorang Peneliti Muda Bidang Instrumentasi Mekanik dan sebagai Lektor Kepala di ISTN Jakarta. 